\title{
Comparison of the Estimated Radiographic Remaining Dentine Thickness with the Actual Thickness Below the Deep Carious Lesions on the Posterior Teeth: An in vitro Study
}

\author{
(D) Nouf AL JHANY, (D) Banin AL HAWAJ, (D) Alanoud AL HASSAN, (D) Zhoor AL SEMRANI, \\ (D) Mohammed AL BULOWEY, (D) Shahzeb ANSARI
}

\section{ABSTRACT}

Objective: Maintaining the remaining dentine thickness (RDT) is crucial because it acts as a protection barrier to the vital pulp tissue against injury and inflammatory products. Based on the relationship between the radiographic RDT (RRDT) and actual RDT (ARDT), we aimed to develop a validated method for guiding dentists in estimating the RDT before caries excavation.

Methods: 30 extracted human teeth were subject to the two-stage experimentation of exposure to cone beam radiography and measurement of actual remaining dentine after sectioning. RRDT and ARDT were recorded, and the difference was statistically analyzed.

Results: A significant difference in the mean values of the estimated difference in dentine thickness was observed $(P<0.05)$. There was no significant difference between molars and premolars as they exhibited a similar range in the difference of the RDT.

Conclusion: It is challenging to find a stable relationship between RRDT and ARDT.

Keywords: Actual dentine, cone beam tomography, estimation, radiographic

\section{HIGHLIGHTS}

Please cite this article as: AL Jhany N, AL Hawaj B, AL Hassan A, AL Semrani Z, AL Bulowey M, Ansari S. Comparison of the Estimated Radiographic Remaining Dentine Thickness with the Actual Thickness Below the Deep Carious Lesions on the Posterior Teeth: An in vitro Study. Eur Endod J 2019; 3: 139-44

Ministry of Health (N.A.J. $\square$ noufaljhany@hotmail.com, B.A.H.) Riyadh Elm University Riyadh, Saudi Arabia; College of Dentistry, (A.A.H., Z.A.S.) Riyadh Elm University Riyadh, Saudi Arabia; Department of Restorative Dentistry (M.A.B.), King Fahad Medical City Riyadh, Saudi Arabia; Department of Preventive Dentistry (S.A.), Riyadh Elm University Riyadh, Saudi Arabia

Received 29 April 2019,

Accepted 23 July 2019

Published online: 26 November 2019 DOI 10.14744/eej.2019.53825

This work is licensed under a Creative Commons Attribution-NonCommercial 4.0 International License.
- Preservation of remaining dentine thickness (RDT) during caries excavation is vital to protect the pulp from injuries.

- Radiographs may help assess RDT to avoid the exposure of the vital tissue.

- We attempted to develop a valid method to estimate the RDT by establishing a relationship between radiographic RDT and actual RDT.

- No constant relationship between RRDT and ARDT was found.

- The risk of pulp exposure is higher when the radiographic RDT is $\leq 0.5 \mathrm{~mm}$.

\section{INTRODUCTION}

Dental caries remains the most prevalent chronic diseases worldwide. Being an infectious microbial disease, the incidence of dental caries is high (1). Dental caries must be removed at the earliest to prevent the harmful effects on the dental pulp. Deferring the treatment for a prolonged period will result in a missed opportunity to save the tooth.

The rate of untreated caries is changing in different countries. The prevalence of caries among 195 countries and territories, along with the subnational locations in Brazil, India, Kenya, Mexico, Saudi Arabia, South Africa, Sweden, the United Kingdom, and the United States, was reported as 1.739 billion in 1990. It increased to 2.521 billion in 2015. The incidence of dental caries was reported as 616 million in 2015 (2). The prevalence and severity of caries are very high in the Kingdom of Saudi Arabia (KSA). Several studies have been conducted in different parts of KSA (3-5), and a very high prevalence and severity of dental caries have been documented. The prevalence of caries was reported as $80.15 \%$ in Riyadh City at male public schools in May 2016 (6).

It is challenging for several dental students and newly graduated dentists to appraise the depth of carious lesions (7) with regard to consistency, as some cavities may look shallow, but it may result in an obligate pulp exposure due to the erroneous estimation of the cavity depth. To prevent 
pulp damage and ensure pulp preservation and conservative treatment, the correct distance should to be determined (8). The reported anxiety among dentists in treating patients with deep carious lesions necessitated further studies (7). These studies aimed to investigate the readiness of the dental practitioners to use less invasive clinical strategies for managing deep lesions (9).

Remaining dentine thickness (RDT) is the thickness of the healthy dentine between the pulpal floor and the roof of the pulp chamber. The thickness needs to be preserved as it acts as a protective barrier to the pulp against mechanical injury and inflammatory products (10). The pulp is more susceptible to the cytotoxic effect of dental materials if the RDT reduces to more than $1.5 \mathrm{~mm}(6,11)$. The quality of the remaining dentine affects the pulp health. During cavity preparation, it is an integral process to conserve the mineral structure. RDT is directly proportional to the health of the human pulp (12).

Remaining dentine affects the quality and longevity of restorations. A long-lasting bonding of restorative materials is achieved through micromechanical retention. Studies have also indicated that the micro-tensile bond strength to dentine significantly improved when the RDT increased (13). Injury of odontoblasts has been reported in teeth with low RDT (14).

Several dentine adhesives have been tested to measure the strength of RDT. A significant correlation was found when the materials were compared with RDT (15). Similarly, the diffusion rates of resin monomers were assessed, and it was found that the rate of diffusion increased where RDT was low (16).

The success rate of stepwise caries excavation after 36-45 months is $88 \%$ (17). A success rate of $37 \%$ at 5 years and a failure rate of $80 \%$ after 10 years were reported for direct pulp capping, following a carious exposure (18).

Clinical experience is a determining factor for the appropriate depth of cavity preparation. Currently, dentists assess the cavity depth by observing the blue shadow of the pulp during caries excavation (19). A variety of methods, such as radiographs (20), prepometer (21), electrical resistance (22), tool maker microscope with a muffle device $(23,24)$, and micro-computed tomography, have been established to assess RDT (8). Conventional radiographs provide a rough estimate of RDT due to its low resolution. Digital radiographs, however, use a higher sensitive plates and provide a clear resolution with sharp images (25). It is the most accessible and accurate method available to the dental practitioner if used appropriately (19).

The RDT estimation is essential for the excavation of caries. Radiographs may help to assess the RDT to avoid the exposure of the vital tissue. Determining a constant relationship between the radiographic RDT (RRDT) and actual RDT (ARDT) would assist dental students and junior dentists to improve their clinical skills when removing dentine in a deep carious lesion.

This study aimed to develop a valid method for guiding dentists and dental students in the estimation of RDT prior to caries excavation by establishing a relationship between the RRDT and ARDT.

\section{MATERIALS AND METHODS}

\section{Inclusion criteria}

1. Permanent posterior teeth

2. Deep carious lesions reaching dentine (radiographic base)

3. Lesion visualized in radiographs (radiographic base)

\section{Exclusion criteria}

1. Incipient or enamel carious lesions (Radiographic base)

2. Deep carious lesions reaching the pulp (Radiographic base)

\section{Methodology}

The institutional review board (IRB) of the Riyadh Colleges of Dentistry and Pharmacy approved the cross-sectional study, with an IRB approval number of RC/IRB/2016/471. Informed consent was not needed for this study.

Fifty human extracted posterior teeth (premolar and molar) were collected from the oral surgery department of King Fahad Medical City. These teeth were examined radiographically after mounting them on an acrylic jaw model. A radiograph was captured using cone beam digital radiography (paralleling technique); the film covered the coronal, middle, and apical third of the tooth. In total, 30 permanent posterior teeth extracted from human carious (14 molars/16 premolars) out of the 50 samples fulfilled the inclusion and exclusion criteria and were selected as the sample.

The sample size was calculated using G*Power (Statistical Power Analysis). The confidence level chosen was 95\% with a $5 \%$ margin of error.

To establish a relationship between the RRDT and ARDT, we

1. Measured RRDT

2. Implemented excavation work for the caries

3. Cross-sectioned the teeth

4. Measured ARDT

5. Compared the RRDT and ARDT measurements.

The teeth were mounted on an acrylic jaw model and radiographed using digital radiography (paralleling technique); the film covered the coronal, middle and apical thirds of the tooth (Fig. 1). A digital software contrast enhancement filter was used for adjusting the radiographs of 30 samples and measuring the estimated RDTs (Fig. 2). For the radiographs, the distance between the cone and tooth was $10 \mathrm{~cm}$, vertical and horizontal angulations were 0 degrees, time of exposure was 1 second each, and an Intraoral Heliodent Plus device (Sirona Dental Systems GmbH, Bensheim, Germany) was used.

Two independent examiners measured RRDT. Excavating the caries was the next step, which was performed by two examiners trained to remove the infected dentine and leave the affected dentine based on the two criteria of discolouration and tactile sensation. Affected dentine is dentine has dark colour, leathery $\backslash$ softer in texture than healthy dentine and hard to remove with spoon excavator. Infected dentine is lighter in colour than affected dentine, very soft, moist, and easy to remove with a spoon excavator. 


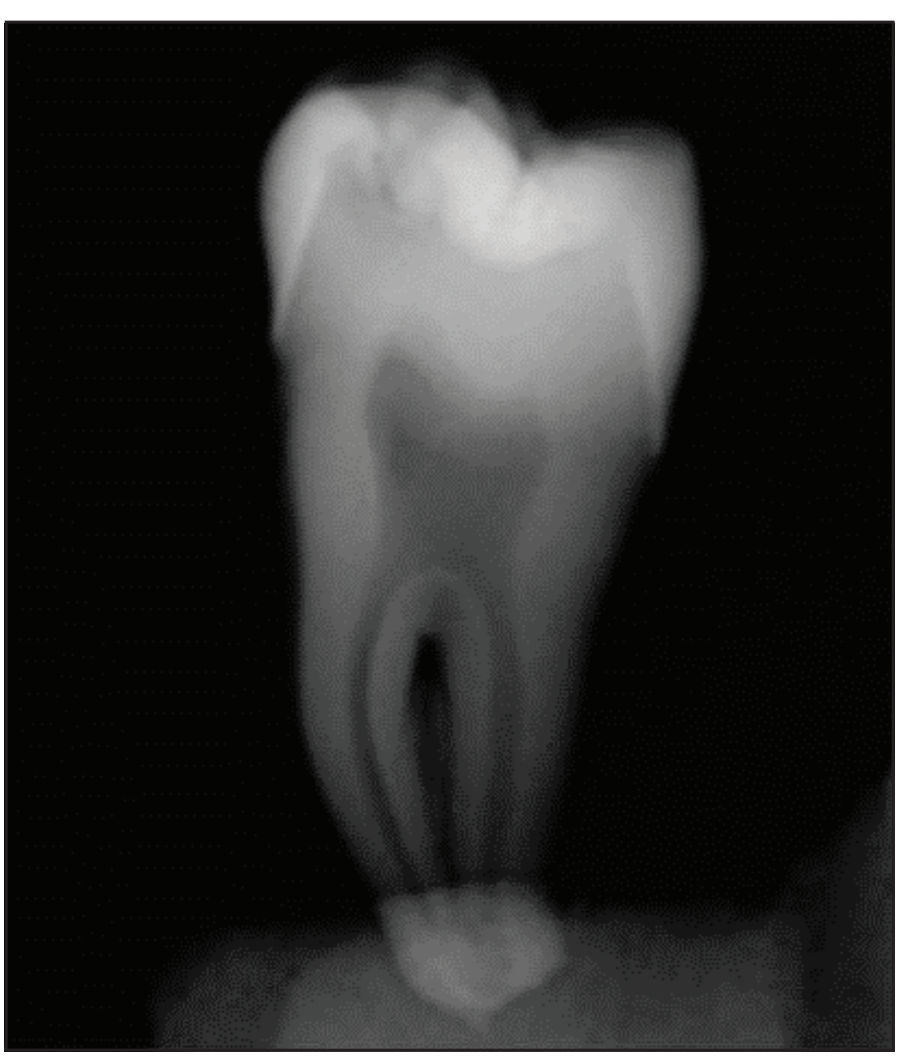

Figure 1. Radiographic sample radiographed via Cone Beam digital radiography (paralleling technique). The film covers the coronal, middle, apical thirds of the tooth. Tooth was mounted on an acrylic jaw model. $34 \times 43 \mathrm{~mm}(96 \times 96 \mathrm{DPI})$

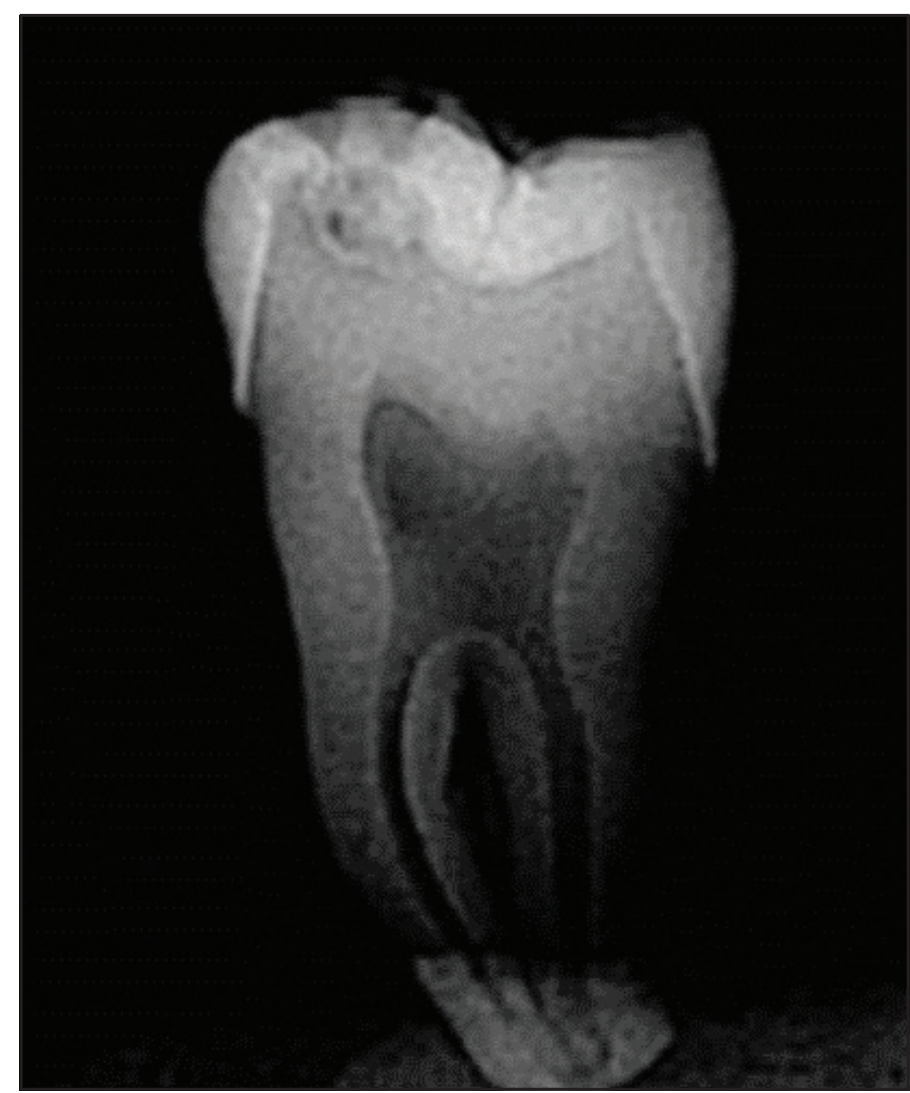

Figure 2. Radiographic image of a molar sample after enhancement of the image qulaity
Caries were removed using a high-speed hand-piece with a round carbide bur size number 2 followed by manual excavation using a spoon excavator. After excavation, the tooth was fixed using the Vise machine (Krason RP et al., 2019) to secure it in place (26) and then cross-sectioned using the high-speed hand-piece with a disc diamond bur (Fig. 3). The same two examiners measured the actual RDT directly using a digital caliper (Fig. 4) from the floor of the cavity (deepest point) until the nearest pulp horn. Collected data were transferred to an excel sheet. The RDTs were evaluated quantitatively.

Further mathematical comparisons were performed on data to discover a relation between the two thicknesses.

\section{Statistical analysis}

The data were analyzed to determine if there is a relationship between the two thicknesses. Using the Statistical Package for Social Sciences software version 19, a Wilcoxon Signed Rank test was performed, as the distribution was found to be skewed.

\section{Reliability testing}

We used the Interclass Correlation Coefficient (ICC) to determine the inter-examiner as well as intra-examiner reliability.

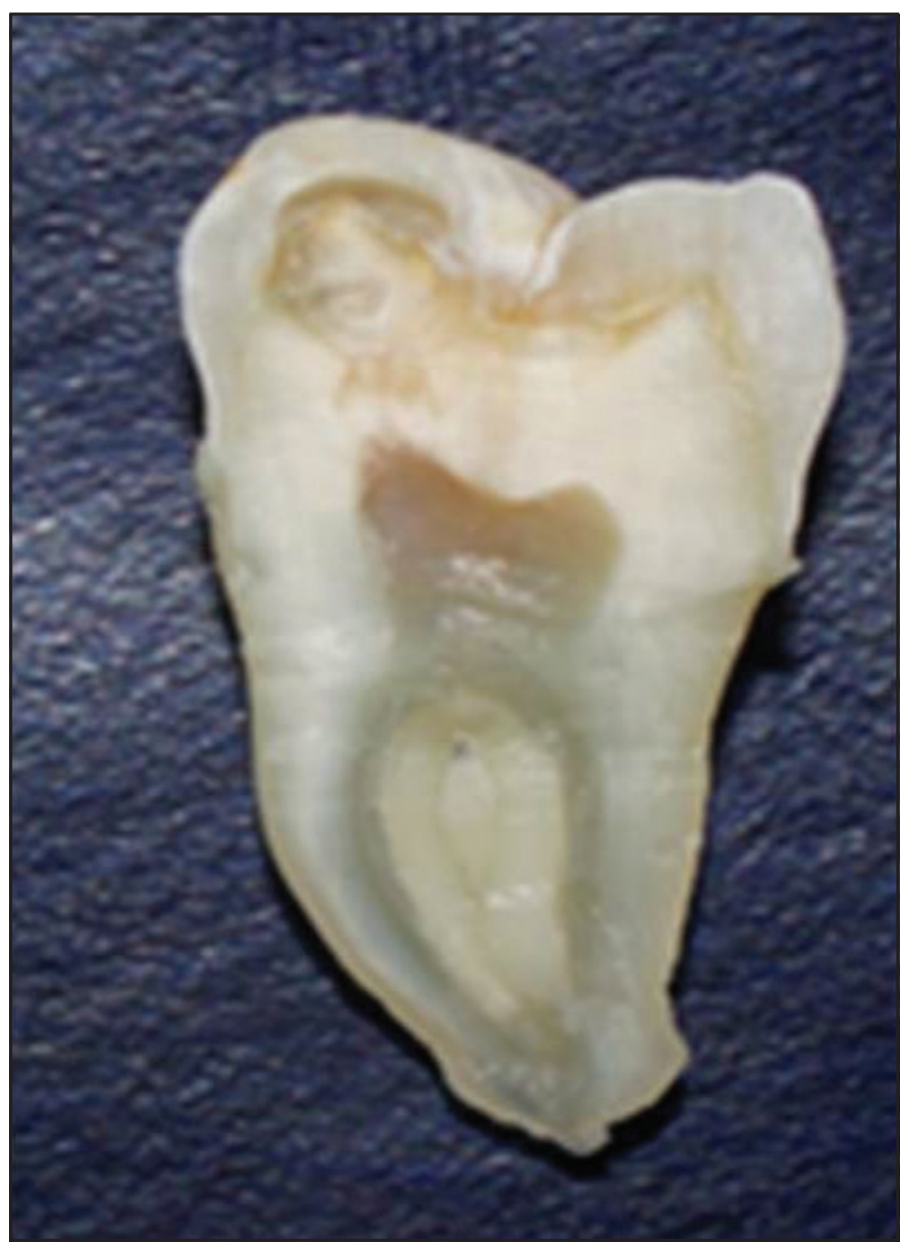

Figure 3. Photograph showing the sectioned part of molar after caries removal with a high speed hand-piece, round carbide bur, and manual excavation using spoon excavator. The tooth was fixed by the Vise machine and cross-sectioned with the high speed hand-piece with a disc diamond bur. $34 \times 47 \mathrm{~mm}(96 \times 96 \mathrm{DPI})$ 


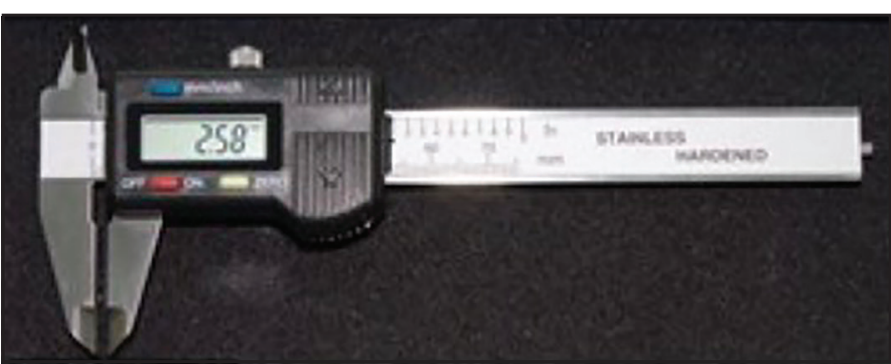

Figure 4. Digital caliper used for measurement $66 \times 26$ mm (96×96 DPI)

The values resulting from the ICC are interpreted as follows: less than 0.5 -poor reliability, $0.5-0.75$-moderate reliability, $0.75-0.90$-good reliability, and greater than 0.90 -excellent reliability.

\section{RESULTS}

Five samples in ARDT had pulpal exposure. Overall, the mean ( \pm standard deviation [SD]) RRDT and ARDT was $1.928( \pm 1.149)$ and $1.707( \pm 1.334)$, respectively. The Wilcoxon Signed Ranks test showed that the mean RRDT was significantly higher than the mean ARDT ( $P=0.000$; Table 1; Fig. 5).

\section{Mean Value:}

\section{Premolar samples}

The mean $( \pm$ SD) RRDT and ARDT was $2.148( \pm 1.249)$ and 1.954 $( \pm 1.208)$, respectively (Table 2$)$. The Wilcoxon Signed Ranks test showed that the mean RRDT was significantly higher than the mean ARDT ( $P=0.000$; Fig. 6).

\section{Molar samples}

The mean $( \pm$ SD) RRDT and ARDT was $1.677( \pm 1.01)$ and 1.425 $( \pm 1.010)$, respectively (Table 2 ). The Wilcoxon Signed Ranks test showed that the mean RRDT was significantly higher than the mean ARDT ( $P=0.001$; Fig. 6).

\section{Premolars}

The estimated RRDT and ARDT are shown in Table 3. For premolars experiencing no pulpal exposure, the RRDT was more than ARDT in all samples. The difference ranged from $0.01 \mathrm{~mm}$ to $0.34 \mathrm{~mm}(0.32-19.6 \%)$.

\section{Molars}

Similar results were recorded for molars (Table 4), with the difference ranging from $0.02 \mathrm{~mm}$ to $0.37 \mathrm{~mm}(2.4-32 \%)$.

\section{Inter-examiner reliability}

Radiographic measurement: 0.80 (good reliability) Measurement after sectioning: 0.85 (good reliability)

TABLE 1. Mean values of RRDT and ARDT

\begin{tabular}{lccccc}
\hline & \multicolumn{5}{c}{ Descriptive statistics } \\
\cline { 2 - 6 } & $\mathrm{n}$ & Mean & SD & Minimum & Maximum \\
\hline RRDT & 30 & 1.9280 & 1.14939 & 0.12 & 3.69 \\
ARDT & 30 & 1.707 & 1.1334 & 0 & 3.38
\end{tabular}

RRDT: Radiographic Remaining Dentine Thickness, ARDT: Actual Remaining Dentine Thickness, SD: Standard Deviation

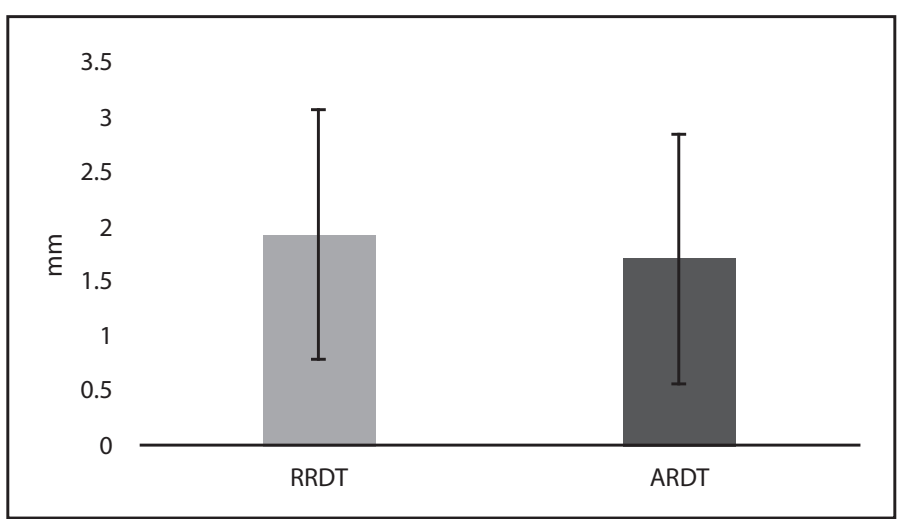

Figure 5. Mean and SD values of RRDT and ARDT

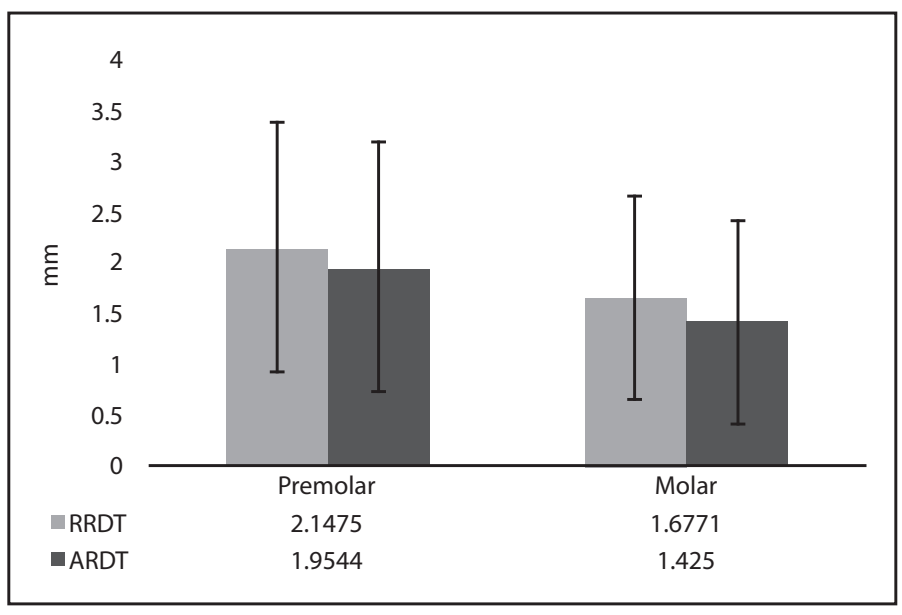

Figure 6. Comparison of mean values for premolars and molars

TABLE 2. Mean value comparisons for premolars and molars

\begin{tabular}{lcccc}
\hline \multicolumn{4}{c}{ Statistics } \\
\cline { 2 - 5 } & RRDT-PM & ARDT-PM & RRDT-M & ARDT-M \\
\hline $\mathrm{N}$ & 16 & 16 & 14 & 14 \\
Mean & 2.1475 & 1.95 & 1.6771 & 1.425 \\
$\mathrm{SD}$ & 1.24899 & 1.20818 & 1.00997 & 1.01010 \\
Minimum & 0.12 & 0 & 0.23 & 0 \\
Maximum & 3.69 & 3.38 & 3.26 & 3.07 \\
\hline
\end{tabular}

RRDT: Radiographic Remaining Dentine Thickness, ARDT: Actual Remaining Dentine Thickness, PM: premolars, M: Molars

\section{Intra-examiner reliability}

Radiographic measurement: 0.92 (excellent reliability) Measurement after sectioning: 0.95 (excellent reliability).

\section{DISCUSSION}

Considering the protection to the pulp provided by dentine, this study aimed to determine the extent of estimation of RRDT over the ARDT of the posterior teeth. The results showed that the pulp of five teeth was exposed. We compared the mean values of ARDT and RRDT as the first step of analysis. It was noted that the mean value for RRDT was higher than ARDT $(P<0.05)$.

Another comparison was done based on the tooth type. We compared the premolars and molars and found that there was a 
TABLE 3. Estimated RRDT and ARDT in premolars

\begin{tabular}{lcccc}
\hline Sample & $\begin{array}{c}\text { RRDT } \\
(\mathrm{mm})\end{array}$ & $\begin{array}{c}\text { ARDT } \\
(\mathrm{mm})\end{array}$ & $\begin{array}{c}\text { Difference } \\
(\mathrm{mm})\end{array}$ & $\begin{array}{c}\text { Difference } \\
(\%)\end{array}$ \\
\hline 1 & 0.16 & 0 & 0.16 & 100 \\
2 & 0.14 & 0 & 0.14 & 100 \\
3 & 1.93 & 1.74 & 0.19 & 9.8 \\
4 & 2.47 & 2.28 & 0.19 & 7.6 \\
5 & 2.47 & 2.23 & 0.24 & 9.7 \\
6 & 3.23 & 3.09 & 0.14 & 4.3 \\
7 & 3.61 & 3.27 & 0.34 & 9.4 \\
8 & 3.69 & 3.38 & 0.31 & 8.4 \\
9 & 3.12 & 3.11 & 0.01 & 0.32 \\
10 & 2.48 & 2.22 & 0.26 & 10.5 \\
11 & 3.59 & 3.30 & 0.29 & 8.1 \\
12 & 0.12 & 0 & 0.12 & 100 \\
13 & 2.75 & 2.46 & 0.29 & 10.5 \\
14 & 1.38 & 1.11 & 0.27 & 19.6 \\
15 & 2.20 & 2.10 & 0.10 & 4.5 \\
16 & 1.02 & 0.98 & 0.04 & 4 \\
\hline
\end{tabular}

RRDT: Radiographic Remaining Dentine Thickness, ARDT: Actual Remaining Dentine Thickness

TABLE 4. Estimated RRDT and ARDT in molars

\begin{tabular}{lcccc}
\hline Sample & $\begin{array}{c}\text { RRDT } \\
(\mathrm{mm})\end{array}$ & $\begin{array}{c}\text { ARDT } \\
(\mathrm{mm})\end{array}$ & $\begin{array}{c}\text { Difference } \\
(\mathrm{mm})\end{array}$ & $\begin{array}{c}\text { Difference } \\
(\%)\end{array}$ \\
\hline 1 & 0.51 & 0 & 0.51 & 100 \\
2 & 0.23 & 0 & 0.23 & 100 \\
3 & 1.22 & 1.00 & 0.22 & 18 \\
4 & 2.47 & 2.28 & 0.19 & 7.7 \\
5 & 3.26 & 3.07 & 0.19 & 5.8 \\
6 & 3.00 & 2.63 & 0.37 & 12 \\
7 & 0.89 & 0.69 & 0.20 & 22 \\
8 & 1.98 & 1.69 & 0.29 & 14.6 \\
9 & 1.02 & 0.69 & 0.33 & 32 \\
10 & 2.55 & 2.22 & 0.33 & 13 \\
11 & 2.88 & 2.63 & 0.25 & 8.7 \\
12 & 0.84 & 0.86 & 0.02 & 2.4 \\
13 & 0.87 & 0.67 & 0.20 & 23 \\
14 & 1.76 & 1.52 & 0.24 & 13.6 \\
\hline
\end{tabular}

RRDT: Radiographic Remaining Dentine Thickness; ARDT: Actual Remaining Dentine Thickness

statistically significant difference between the ARDT and RRDT. RRDT was higher than ARDT. Similar findings were seen for the molars (RRDT higher than ARDT). RDT is expressed in millimeter, and their ranges are mentioned under the results section.

No constant estimation of ARDT was found. The values ranged widely, suggesting a lack of correlation. However, all the teeth with a RRDT of $\leq 0.5 \mathrm{~mm}$ encountered pulp exposure.

A study by Lancaster, Craddock, and Carmichael (2011) revealed that there was no clear estimation of the dimension of the RDT from a regular digital periapical radiograph (20). Cone beam computed tomography was used in this study, however, we could not achieve a specific range of estimation.

A study conducted by Hatton et al (2007) used both ultrasonic micrometer and caliper measurements to assess RDT (27).
However, our study used only caliper measurements. The referenced study showed more accurate results when using ultrasonic measurements.

A Digital Caliper (also known as a Digital Vernier Caliper) is a precision instrument that can be used to measure internal and external distances extremely accurately. Measurements are read from a liquid crystal display screen. The instrument is commonly used in various dental studies (28). The future of measuring RDT is optimistic however, as the use of optical coherence tomography is trending, achieving higher accuracy in these measurements will contribute to the skill improvement of dentists (29).

The limitations of the study include the angulation of mounted teeth. In addition, the periapical radiograph has 5\% magnification (30). Human errors are considered one of the limitations of this study because it is challenging to measure the exact point at two instances. In addition, the study used only permanent premolar and molar teeth.

\section{CONCLUSION}

Within the limitations of the study, it can be concluded that determining a constant relationship between RRDT and ARDT remains a challenge. In addition, the risk of pulp exposure is higher when the RRDT is $\leq 0.5 \mathrm{~mm}$. There was no significant difference between molars and premolars as they exhibited a similar range in the difference of the RDT.

\section{Disclosures}

Conflict of interest: The authors do not have any financial interest in any of the companies whose products are included in this article.

Ethics Committee Approval: The study was approved by the IRB of the Riyadh Colleges of Dentistry and pharmacy (RC/IRB/2016/471).

Peer-review: Externally peer-reviewed.

Financial Disclosure: None declared.

Authorship contributions: Concept - N.A.J., B.A.H., A.A.H., Z.A.S., M.A.B., S.A.; Design - N.A.J., B.A.H., A.A.H., Z.A.S., M.A.B., S.A.; Supervision - M.A.B., S.A.; Funding - Not applicable; Materials - N.A.J., B.A.H., A.A.H., Z.A.S.; Data collection \&/or processing - N.A.J., B.A.H., A.A.H., Z.A.S.; Analysis and/or interpretation - M.A.B., S.A.; Literature search - N.A.J., B.A.H., A.A.H., Z.A.S.; Writing N.A.J., B.A.H., A.A.H., Z.A.S., M.A.B., S.A.; Critical Review - N.A.J., B.A.H., A.A.H., Z.A.S., M.A.B., S.A.

\section{REFERENCES}

1. Fleming $\mathrm{E}$, Afful J. Prevalence of Total and Untreated Dental Caries Among Youth: United States, 2015-2016. NCHS Data Brief 2018; (307):1-8.

2. Kassebaum NJ, Smith AGC, Bernabé E, Fleming TD, Reynolds AE, Vos T, et al. Global, Regional, and National Prevalence, Incidence, and DisabilityAdjusted Life Years for Oral Conditions for 195 Countries, 1990-2015: A Systematic Analysis for the Global Burden of Diseases, Injuries, and Risk Factors. J Dent Res 2017; 96(4):380-7.

3. Aljanakh M. Prevalence and severity of dental caries among public school students aged 16-18 in Hai'l, Kingdom of Saudi Arabia. Int J Health Sci (Qassim) 2017; 11(3):50-3.

4. Al-Ansari A. Prevalence, severity, and secular trends of dental caries among various saudi populations: A literature review. Saudi Journal of Medicine and Medical Sciences 2014;2:142-50.

5. Farooqi FA, Khabeer A, Moheet IA, Khan SQ, Farooq I, ArRejaie AS. Prevalence of dental caries in primary and permanent teeth and its relation with tooth brushing habits among schoolchildren in Eastern Saudi Arabia. Saudi Med J 2015; 36:737-42. 
6. Tomer AK, Miglani A, Chauhan P, Malik N, Gupta A. Residual dentine thickness International Journal of Applied Dental Sciences 2016; 2(4):96-9.

7. Obarisiagbon A, Azodo CC, Omoaregba JO, James BO. Clinical anxiety among final year dental students: The trainers and students perspectives. Sahel Medical Journal 2013; 16(2):64-70.

8. Majkut P, Sadr A, Shimada Y, Sumi Y, Tagami J. Validation of Optical Coherence Tomography against Micro-computed Tomography for Evaluation of Remaining Coronal Dentin Thickness. J Endod 2015;41:1349-52.

9. Schwendicke F, Stangvaltaite L, Holmgren C, Maltz M, Finet M, Elhennawy $\mathrm{K}$, et al. Dentists' attitudes and behaviour regarding deep carious lesion management: a multi-national survey. Clin Oral Investig 2017;21:191-8.

10. Wegehaupt F, Betke H, Solloch N, Musch U, Wiegand A, Attin T. Influence of cavity lining and remaining dentin thickness on the occurrence of postoperative hypersensitivity of composite restorations. J Adhes Dent 2009; $11(2): 137-41$.

11. Stanley HR. Dental iatrogenesis. Int Dent J 1994; 44(1):3-18.

12. Murray PE, Smith AJ, Windsor LJ, Mjör IA. Remaining dentine thickness and human pulp responses. Int Endod J 2003; 36(1):33-43.

13. Inoue $S$, Van Meerbeek B, Abe Y, Yoshida Y, Lambrechts P, Vanherle G, et al. Effect of remaining dentin thickness and the use of conditioner on micro-tensile bond strength of a glass-ionomer adhesive. Dent Mater 2001; 17(5):445-55.

14. Murray PE, About I, Lumley PJ, Franquin JC, Remusat M, Smith AJ. Cavity remaining dentin thickness and pulpal activity. Am J Dent 2002;15:41-6.

15. Perinka L, Sano H, Hosoda H. Dentin thickness, hardness, and Ca-concentration vs bond strength of dentin adhesives. Dent Mater 1992; 8(4):22933.

16. Hamid A, Hume WR. The effect of dentine thickness on diffusion of resin monomers in vitro. J Oral Rehabil 1997; 24(1):20-5.

17. Maltz M, Oliveira EF, Fontanella V, Carminatti G. Deep caries lesions after incomplete dentine caries removal: 40-month follow-up study. Caries Res 2007; 41(6):493-6.

18. Ricketts D. Management of the deep carious lesion and the vital pulp dentine complex. Br Dent J 2001; 191(11):606-10.
19. Sinescu C, Negrutiu ML, Bradu A, Duma VF, Podoleanu AG. Noninvasive Quantitative Evaluation of the Dentin Layer during Dental Procedures Using Optical Coherence Tomography. Comput Math Methods Med 2015;2015:709076.

20. Lancaster PE, Craddock HL, Carmichael FA. Estimation of remaining dentine thickness below deep lesions of caries. Br Dent J 2011; 211(10):E20.

21. Purton DG, Chandler NP, Monteith BD, Qualtrough AJ. A novel instrument to determine pulp proximity. Eur J Prosthodont Restor Dent 2009; 17(4):30-4.

22. Yoshida $\mathrm{H}$, Tsuji $\mathrm{M}$, Matsumoto $\mathrm{H}$. An electrical method for examining remaining dentine thickness. J Dent 1989; 17(6):284-6.

23. Pilo R, Corcino G, Tamse A. Residual dentin thickness in mandibular premolars prepared with hand and rotatory instruments. J Endod 1998; 24(6):401-4.

24. Katz A, Wasenstein-Kohn S, Tamse A, Zuckerman O. Residual dentin thickness in bifurcated maxillary premolars after root canal and dowel space preparation. J Endod 2006; 32(3):202-5.

25. Bansal GJ. Digital radiography. A comparison with modern conventional imaging. Postgrad Med J 2006; 82(969):425-8.

26. Krason RP, Chick JP. Method of machining and vise for use therein Available at: https:/patentimages.storage.googleapis.com/83/99/aa/ f4338b75e6dd4e/US4529183.pdf. Accessed Nov 25, 2019.

27. Hatton JF, Pashley DH, Shunk J, Stewart GP. In vitro and in vivo measurement of remaining dentin thickness. J Endod 1994; 20(12):580-4.

28. Sharma S, Thakur SL, Joshi SK, Kulkarni SS. Measurement of gingival thickness using digital vernier caliper and ultrasonographic method: a comparative study. J Investig Clin Dent 2014; 5(2):138-43.

29. Fujita R, Komada W, Nozaki K, Miura H. Measurement of the remaining dentin thickness using optical coherence tomography for crown preparation. Dent Mater J 2014; 33(3):355-62.

30. Kiarudi AH, Eghbal MJ, Safi Y, Aghdasi MM, Fazlyab M. The applications of cone-beam computed tomography in endodontics: a review of literature. Iran Endod J 2015; 10(1):16-25. 